\title{
Bachelor of Commerce Programme and employability of University of Venda graduates, South Africa
}

\author{
${ }^{*}$ Emmanuel K. Oseifuah, Agyapong B. Gyekye, George NovisiKwadzo, Vukor-Quarshie \\ University of Venda, South Africa \\ *oseifuah@univen.ac.za
}

\begin{abstract}
Since its establishment two and half decades ago, the School of Management Sciences at the University of Venda (UNIVEN) has produced hundreds of Bachelor of Commerce (BCOM) graduates for the South African work force. Yet the School has had no formal feedback from its graduates regarding the relevance, usefulness, strengths and weakness of its BCOM programmes. The purpose of this study was to assess the impact of the BCOM (Accounting) programme on job prospects of UNIVEN graduates. A structured questionnaire was sent to a sample of 61 graduates of UNIVEN's BCOMA programme through the Snowball technique of tracing survey respondents. The questionnaire sought the participating graduates' opinions on several aspects of their educational experience at Univen including adequacy of the training and employability, among others. The study used the IBM SPSS version 21 to analyse the study data. The key findings of the study suggest that the components of the BCOMA programme that need major improvement to increase the employability of graduates are training in practical skills, using computers in Accounting training, as well as improvement in teaching and delivery methods. The study also found that modules offered in the BCOM programme were relevant to the graduate's job needs.
\end{abstract}

Keywords: Bachelor of Commerce, Graduates, Employability, South Africa, University of Venda

\section{Introduction}

It is generally acknowledged that a purposive and effective tertiary education and training system is fundamental to generating competent and essential high level skills and knowledge that are vital for the socio-economic development of a country (Harvey, 2000). A highly skilled workforce is a positive catalyst for innovation, leadership and management. The absence of a sound and teleological education system stymies economic planning, job creation, poverty alleviation as well as the attainment of equitable social development goals. Since its establishment two and half decades ago, the School of Management Sciences at the University of Venda (UNIVEN) has produced hundreds of Bachelor of Commerce (BCOM) graduates for the South African work force. Yet the School has had no formal feedback from its graduates regarding the relevance, usefulness, strengths and weakness of its BCOM programmes. The School does not know how its BCOM graduates are performing in their places of work, nor does it know the strengths and weaknesses of its programmes as perceived by graduates. This situation is due primarily to the fact that neither the institution nor the Schools of Management Sciences had any monitoring system in place for getting feedback from their graduates and/or their employers relating to the "fitness for purpose", relevance, strengths and weaknesses of their programmes. Some media reports have questioned the quality of the UNIVEN Bachelor of Commerce (Accounting) general degree. They claim that the programme is of a low quality and that the graduates are unemployable. (See City Press, Sunday 3 November, 2007; Sowetan, Tuesday 13 November, 2007). The indictment again is that the graduates possess inferior skills. Such damning indictments from the press have created a poor public perception about UNIVEN's programmes. To what extent are these damning indictments accurate? To date no systematic study has been carried out to assess the impact of BCOM programmes in terms of the vocational destination of these graduates. This calls for an empirical study that will provide accurate and verifiable data that could be scientifically analysed to determine the adequacy or otherwise of the BCOM degree programmes. The purpose of the study is to fill this gap in the literature by analysing the relevance and usefulness of the UNIVEN's BCOM Accounting programme in meeting the job needs of graduates

\section{Aim and Objectives of the study}

Aim of the study: The aim of the study was to assess the impact of the BCOM (Accounting) programme ingenerating competent, skilled, and knowledgeable graduates crucial for the socio-economic development of South Africa and the rest of the world. 
Objectives of the study: The objectives of the study are to:

- Determine the extent of employment success of UNIVENBCOM graduates.

- Determine the extent to which the BCOM degree curricula adequately equip graduates with basic competencies and skills required for effective job performance.

- Ascertain the extent to which the teaching methods and study conditions in UNIVENadequately equip graduates with relevant practical exposure, skills and competencies necessary for enhanced/competent job performance in their places of work.

\section{Literature Review}

Tracer studies, is considered an appropriate means of evaluating the results of the education and training provided at a given institution (AAU, 2002). The International Labour Organisation (ILO) Thesaurus defines a tracer study as an impact assessment tool where the "impact on target groups is traced back to specific elements of a project or programme so that effective and ineffective project components may be identified." Clearly, a tracer study should enable tertiary institutions to get information from graduates and employers regarding the adequacy of educational programmes. The information will also serve as a basis for future planning activities. In a knowledge economy, one of the critical objectives of tertiary education and training is to prepare students for future employment. There is therefore a vital and essential nexus between tertiary education and employment (Harvey, 2000). Since the 1980's there has been a growing body of literature on the relevance of higher education to the world of work in developed countries (Schomburg, 2003). A number of studies have also been carried out in Africa. Schomburg (2003) reported that from 1996 to 2000, the Association of African Universities (AAU) has funded 15 tracer studies, which were conducted in 7 African countries (Cameroon, Ghana, Kenya, Malawi, Nigeria, Uganda and Tanzania). For example, Zembere and Chinyama (1996) analysed the changes in the career pattern of University of Malawi graduates and found that graduates were satisfied with the training provided by the university in terms of teaching quality, course content and the knowledge gained. In addition, respondents rated the use of professional knowledge and skills acquired during studies as a very important factor in job satisfaction. The findings further show that English communication skills were seen as very important across all degrees. Similarly, Ugwuonah and Omeje (1998) conducted a tracer survey on higher education and the demands of manpower development in the Nigerian manufacturing sector. They investigated the adequacy or otherwise of contemporary higher education in the context of manpower development needs of the manufacturing sector in Nigeria. The findings revealed the following: graduates were satisfied with the study environment including teaching quality of lecturers, contacts with fellow students and academic advice offered.

In the case of Tanzania, Kaijage (2001) analysed the relevance of the various programmes offered by the University of Dar es Salam's Faculty of Commerce and Management. Data was collected on graduates' employment status and the relevance, strengths and weaknesses of their training. The results show that BCom graduates generally considered the strong contacts between students to be the greatest benefit of the program, followed by the quality of lectures and the sound structure of the BCom programme. The present study on a South African tertiary institution adds to the body of research in Africa which assesses the effectiveness of tertiary education in meeting the employment needs of graduates. A number of studies have been carried out in South Africa. For example, the Human Sciences Research Council (HSRC, 2000) analysed the first employment experiences of new graduates. The survey which involved about 8000 university graduates (who had graduated between 1991 and 1995), found that more than half (59\%) of the respondents, who tried to find employment after obtaining a degree did so immediately. The study, however, found that not all graduates were successful in their search for a first job. The most successful ones had studied medical sciences (91\% success rate) and engineering (77\%). Graduates in humanities and arts (34\%), law (40\%) and natural sciences (48\%) were less successful in finding employment immediately after graduation. More than two thirds (65\%) of respondents graduating from the historically white universities found employment immediately as opposed to $28 \%$ of the respondents from the historically black universities. Differences were found between population groups, only $28 \%$ of the 142 black graduates and $34 \%$ of the coloured graduates immediately found employment, as opposed to $56 \%$ of the Indian graduates and $67 \%$ of the white graduates.

A recent study by Shongwe and Ocholla (2011) traced Library and Information Science (LIS) graduates who graduated from the Department of Library and Information Science (now Information Studies) at the 
University of Zululand between 2000 and 2009. A questionnaire consisting of both structured and unstructured questions was used as the main research instrument. A total of 50 graduates participated in the study. The study found that most LIS graduates were employed in the public sector, mainly in national, provincial and municipal libraries. Graduates were happy with the skills and knowledge they obtained from the LIS curriculum, but unhappy with the curriculum itself, often for contradictory reasons. Like most tracer studies, this study addresses similar questions: Are graduates employable? Is the curriculum relevant? What are the perceptions of graduates and employers about the graduates 'skills, knowledge and education?

\section{Methodology}

Sampling Frame and Strategies for Tracing Graduates: At the time this study was conducted at the end of 2011, there were over 1350 BCOM (Accounting) graduates who had completed their undergraduate degree programme between 2001 and 2011 from the School of Management Sciences (SMS), at the University of Venda (Office of the School Administrator, School of Management Sciences, December 2011). Selection and tracing of accounting graduates presented a major challenge to the research effort due to lack of reliable database, including current contact addresses, of SMS graduates. A number of approaches were therefore adopted to trace the Accounting graduates. First, from their records at the School of Management Sciences (SMS), addresses that graduates gave as permanent addresses at the time of registration, or in situations where graduates had left their current address were used to trace them. Using this method proved not to be useful as the response rate was very poor. An alternative approach to tracing the Accounting graduates which improved the response rate, was tracing these graduates through the School of Management Sciences Alumni Association members, the contact addresses and telephone numbers of whom were available to the research team. Known in research circles as the Snowball Technique, the Alumni Association members who are Accounting graduates were sent questionnaires to complete, and were also requested to assist in locating other graduates.

Data Collection Instrument: After graduates were located, a set of structured questionnaires were sent to them via email or through the postal addresses of their places of work. Face to face interviews were also used to collect the data especially in Gauteng Province. The questionnaire asked questions on graduates' socio-biographical data, year of graduation from UNIVEN, area of specialisation, and factors that informed their decision to choose UNIVEN, current employment status, where employed and how long it took the graduate to get a job after graduation. It also solicited information on:

- their opinions about the adequacy of the training received from UNIVEN, employability and their ability to perform their jobs

- the extent to which they used knowledge and skills acquired from BCOM programme at UNIVEN

- aspects of the BCOM programme that needed improvement to better prepare graduates for the job market

- how they rate the study delivery and study conditions at UNIVEN

After several follow ups on the questionnaires sent to graduates, we received 61 responses from about 115 graduates constituting a response rate of $53.04 \%$

\section{Data Analysis and Results}

After collecting the data, a code book was developed and data captured using the SPSS statistical software. The data was subsequently analysed and tables generated for results which follow, using the same SPSS programme.

Socio-demographic profile of BCOM (Accounting) Graduates: Of the 61 graduates that participated in this study, $54 \%$ were females, with males making up $46 \%$ of participants. The above distribution is not surprising as it mirrors the current trends in enrolment at the University of Venda by gender, which stands at about $51 \%$ female and $49 \%$ male, (in the 2012 academic year). Fifty seven per cent of the graduates/respondents were between 25-29 years of age, 23\% were between $30-34$ years while $15 \%$ were between 20-24 years of age. One of the objectives of this study was to determine whether there were any significant differences in gender and academic performance. Table 1 clearly displays that there were differences in academic performance or number of years taken to graduate. It took approximately 4 years for males to graduate from a three-year BCOM (Accounting) degree and approximately 5 years for 
females to graduate. However, this difference had to be tested to know whether the difference is due to sampling variation or whether there is an actual difference.

Table 1: Gender and Academic Performance

\begin{tabular}{|c|c|c|c|c|c|c|}
\hline \multirow{3}{*}{$\begin{array}{l}\text { No. of years taken to } \\
\text { obtain a 3-year BCom } \\
\text { (Acc) degree }\end{array}$} & Gender & $\mathbf{N}$ & Mean & Std. Deviation & $\begin{array}{l}\text { Std. } \\
\text { Mean }\end{array}$ & Error \\
\hline & Male & 27 & 3.8889 & 1.36814 & .26330 & \\
\hline & Female & 34 & 4.8824 & 1.93476 & .33181 & \\
\hline
\end{tabular}

In order to establish whether there was a significant difference in the number of years taken to graduate with respect to gender, the findings from the $t$-test of difference between two means in Table 2 confirmed that indeed males took one year less than females to attain a UNIVENBCOM (Accounting) degree. In addition, the median number of years taken to graduate a three-year UNIVENBCOM (Accounting) degree was 4 years.

Table 2

\begin{tabular}{llllll}
\hline $\mathbf{t}$ & Df & Sig. (2-tailed) & Mean Difference & $\begin{array}{l}\text { Std. } \\
\text { Difference }\end{array}$ & Error \\
\hline-2.256 & 59 & .028 & -.99346 & .44038 & \\
\hline
\end{tabular}

It is obvious from the tables above that there exists a significant gender-based difference in graduation rates in the Univen BCom (Accounting) degree. The reasons for this divergence are, however, extrinsic to this study.

Factors influencing decision to enrol at Univen: The study also sought to establish the main factors that motivated graduates to enrol at the University of Venda for BCOM (Accounting) studies. Table 3 summarises the mean ranking of the factors that enticed graduates to first enrol at UNIVEN for their BCOM (Accounting) studies. A lower mean ranking means the response is in the affirmative (i.e. the factor that influenced the graduate most in choosing to enrol at Univen) and vice versa (see scale of table 3 below). From the responses in table 3.3, the graduates indicated that affordability (with mean ranking of 2.11) above all else, was the singular most important factor that motivated graduates to enrol at Univen.

Table 3: Factors Influencing Decision to Enrol at Univen

\begin{tabular}{ll}
\hline Ranks & Mean Rank \\
Factors & 2.11 \\
\hline Affordability for family & 2.22 \\
Advice by parents & 2.43 \\
Availability of Course offer at Univen & 2.55 \\
Admission standards and prior grades & 2.81 \\
Reputation of the University/Department & 2.84 \\
Vicinity to parent's home & 2.85 \\
Areas of specialisation provided & 3.04 \\
Practice oriented study programme & 3.30 \\
Availability of scholarship at Univen & 3.41 \\
Influence of peers & 3.42 \\
\hline Availability of accommodation at Univen
\end{tabular}

Question: How important were the following factors to your decision to enrol at Univen? Scale from $1=$ to a very high extent, $2=$ to $a$ high extent, $3=$ to some extent, $4=$ barely, $5=$ Not at all important.

Coming from low income families, students will naturally be advised by parents, who provide the financial resources for the student's education, to enrol in Univen, in particular if the student's preferred course is available at UNIVEN such as BCOM (Accounting). Consequently the mean rank for advice of parents is also low (2.22), and that for availability of course offer at UNIVEN is 2.43. The Friedman test was employed in Table 4 below to ascertain if there were differences in factors motivating graduates to enrol at UNIVEN for their BCOM (Accounting) degree. It tests whether there is an overall statistically significant difference between mean ranks of the factors that motivated the graduates' to enrol at UNIVEN in Table 3. 
Table 4: Factors motivating graduates to enrol for BCom at UNIVEN

\begin{tabular}{ll}
\hline Test Statistics & \\
\hline $\mathrm{N}$ & 59 \\
Chi-Square & 55.356 \\
Df & 10 \\
Asymp. Sig. & .000 \\
\hline
\end{tabular}

The Chi-Square statistic in table 4.4 is statistically significant implying that there were clear differences in the sundry factors that motivated graduates' decision to enrol at Univen. For reporting purposes the Friedman test is presented as follows: $\mathrm{X} 2(10)=55.356, \mathrm{p}=.000$

Employment Status of BCOM (Accounting)graduates: Responses from the graduates indicated that about $76 \%$ of them were permanently employed with the remaining $23 \%$ either temporarily employed or employed on part-time basis. Many of the graduates who were temporarily employed or employed on part-time basis indicated that they were pursuing further studies in order to enhance their chances of securing jobs of their preference.

Employment Success of UNIVENBCOM (Accounting) graduates: The distribution of graduates with respect to the time it took to find their first job is displayed in Table 5.

Table 5: Distribution of Time taken to find first job after graduation

\begin{tabular}{llll}
\hline & Frequency & Percent & Cumulative Percent \\
\hline$<6$ months & 26 & 42.6 & 42.6 \\
6-12 months & 15 & 24.6 & 67.2 \\
13-24 months & 12 & 19.7 & 86.9 \\
$>$ 2 years & 8 & 13.1 & 100.0 \\
Total & 61 & 100.0 & \\
\hline
\end{tabular}

It can be inferred from the table that a little more than $40 \%$ of BCOM (Accounting) graduates found their first employment within six months of graduating, and about $67 \%$ of graduates found employment within a year of graduation. Generally, it took UNIVENBCOM (Accounting) graduates what be viewed as a reasonable amount of time to find their first job after graduation.

Employment destination: Table 6 deals with employment destination or sources of employment on UNIVEN BCom graduates.

Table 6: Distribution of Source of Employment

\begin{tabular}{llll}
\hline & Frequency & Valid Percent & Cumulative Percent \\
\hline Public sector & 37 & 60.7 & 60.7 \\
Parastatal & 9 & 14.8 & 75.4 \\
Private sector & 14 & 23.0 & 98.4 \\
NGO & 1 & 1.6 & 100.0 \\
Total & 61 & 100.0 & \\
\hline
\end{tabular}

The table indicates that government directly or indirectly (Parastatals) employed more than threequarters of our graduates. It further shows that the private sector employed only $23 \%$ of the graduates. Because the private sector is usually the major creator of employment it was expected that the private sector will absorb more graduates into the job market. The question, therefore, arises whether the skills acquired by UNIVENBCOM (Accounting) graduates are attractive enough for the private sector or do the graduates simply evince preference for the public sector?

Graduate opinion on training, employability and job performance: Graduates were asked to express their opinions on the adequacy of training, employability and ability to perform their jobs. The mean ranking of the graduates opinions are presented in Table 7. A higher mean ranking implied a response in the affirmative and vice versa as shown in the table (see scale below table 7). 
Table 7: Mean Ranking of Graduates Perception about Training, Employability and Their ability to perform their jobs

\section{Ranks}

Themes

My training adequately prepared me for work

Mean Rank

My employer was satisfied with my level of knowledge \& skill

3.63

It is easy for me to get a job

4.22

I can easily be trained to improve my level of skill

3.31

4.47

I find myself to be very effective in my current job

Can easily change employers within my area of specialisation

3.79

Question: What is your opinion about the following statements in relation to the adequacy of BCOM graduates' training, employability and their ability to perform their jobs? Scale: 1=strongly disagree, 2=disagree, $3=$ Not applicable, 4=agree, 5=strongly agree

The mean rankings in table 3.7 show that most graduates felt that they can improve their levels of skill (mean rank value of 4.47). However, they indicated that it is not easy to get a job (mean rank value of 3.31). The Friedman test was employed in Table 3.8to ascertain if there were differences in opinions with respect to the themes in table 3.7. It tests whether there is an overall statistically significant difference between mean ranks of the graduates' opinions on the themes in table 3.7

Table 8: Differences in Graduates' Perception about Training, Employability and ability to perform their jobs

\begin{tabular}{ll}
\hline Test Statistics & \\
\hline $\mathrm{N}$ & 56 \\
Chi-Square & 60.274 \\
$\mathrm{Df}$ & 5 \\
Asymp. Sig. & .000 \\
\hline
\end{tabular}

The Chi-Square statistic in table 4.8 is significant and indicates that there were clear differences in opinions. For reporting purposes the Friedman test is presented as follows: $X^{2}(5)=60.274, p=.000$. Thus there was a statistically significant difference in the graduates' opinion on training, employability and ability to perform their jobs

Factors influencing graduate employability: To further evaluate the value of the BCOM degree from UNIVEN in their job search, graduates were asked to express their opinion on the importance of a number of factors in securing a job. The figures against each theme in table 9 represent ranking of factors that enabled UNIVENBCOM graduates to secure employment. The mean ranking of each theme is different signifying that some factors contributed more to securing employment than the others. A lower mean ranking implies a response in the affirmative and vice versa (see scale below table 9)

Table 9: Mean Ranking of Factors that Influenced Graduates being employed

\begin{tabular}{ll}
\hline Factors influencing employment & Mean Rank \\
\hline Field of study & 2.42 \\
Grades at university & 2.99 \\
Reputation of the university & 3.56 \\
Previous work experience & 3.69 \\
Personality & 2.35 \\
\hline
\end{tabular}

Question: In your opinion, how important were the following factors for your being employed? Scale: $1=$ To a very high extent, $2=$ To a high extent, 3=To some extent, 4=Barely, 5=Not at all important.

The mean rankings revealed that graduates perceived one's personality (mean rank of 2.35) and the field of study at varsity i.e. Accounting (mean rank of 2.42) as the primary factors that enticed employers. However graduates perceived the reputation of the university (mean rank of 3.56) in playing a very minimal role in graduate employability. The Friedman test was used to evaluate whether these 
differences in mean rankings were significant. The results of the test were as follows: $X^{2}(4)=36.125$, $\mathrm{P}=.000$. Thus the Friedman test confirmed that there was a significant difference in mean ranking. Thus some of the listed factors contributed to graduates securing employment more than others.

Teaching and Learning Provision and Support Facilities: BCom (Accounting) graduates' responses with regard to pedagogy and support facilities at UNIVEN are indicated in Table 10. The figures represent mean ranking of factors that describe the teaching \& learning provision and support facilities available to UNIVEN BCom (Accounting) students. A lower mean ranking implied a response in the affirmative and vice versa (see scale below 10 ).

Table 10: Rating of Teaching \& Learning provision and Support Facilities

\begin{tabular}{ll}
\hline Ranks & Mean Rank \\
Teaching \& Learning provision and Support facilities & 2.24 \\
\hline Assistance for final examination & 2.31 \\
Contact Hours with lecturers & 3.04 \\
Participate in research projects & 2.50 \\
Grading systems in Univen & 2.00 \\
Contact with fellow students & 3.04 \\
Opportunity for students to influence university policy & 2.57 \\
Library facilities & 3.25 \\
Accommodation facilities on campus & 3.24 \\
Catering facilities on campus & 3.12 \\
\hline Lecture venues
\end{tabular}

Question: How do you rate the study provision and study conditions you experienced at Univen? Scale: $1=$ very good, $2=$ good, $3=$ average, $4=$ bad, $5=$ very bad

From Table 10, the three most important factors which graduates identified were the opportunity to meet fellow students on campus, assistance for final examination and access to lecturers for consultations (mean ranking of 2.00, 2.24 and 2.31 respectively). In the same vein, the more pressing conditions were poor accommodation facilities, access to catering facilities, and also insufficient lecture venues. These problems are justified by the relatively large mean rankings (mean rankings of $3.25,3.24$ and 3.12 respectively). The results of the Friedman test is $X^{2}(9)=103.479, p=0.000$ and it indicates that there is a significant difference in student opinions about the several teaching \& learning provision and support facilities.

Proposals to Improve Components of the BCOM (Accounting) Programme: Graduates were asked to rank the areas or topics in their training at UNIVEN that should be improved to better prepare graduates for the job market. Table 11 displays the ratings, measured by mean rankings, of the extent to which components of the BCOM programme need to be improved in order to increase employability of graduates. A lower mean ranking implies a response in the affirmative (i.e. needs major improvement) and vice versa (see scale below Table 11)

Table 11: Rating of the degree to which the Components of the BCOM programme need to be improved to better prepare Graduates for the Job market

\begin{tabular}{ll}
\hline Ranks & \\
Component of BCOM Programme & Mean Rank \\
\hline Knowledge of Instructor (Theory) & 2.19 \\
Training in practical skills & 1.57 \\
Course content & 2.15 \\
manuals & 2.30 \\
Textbooks & 2.28 \\
Access to Computer Labs & 1.73 \\
Teaching and delivery methods & 2.08 \\
Instructors' practical skills & 2.11 \\
Programme duration & 2.66 \\
\hline
\end{tabular}


Question: Rate the extent to which the following components of the BCOM programme should be improved to prepare graduates for the job market. Scale: $1=100 \%$ improvement, $2=75 \%$ improvement, $3=50 \%$ improvement, $4=25 \%$ improvement and $5=$ no improvement.

Training in practical skills scored a lower mark (mean rank value=1.57) coupled with access to computer labs (1.73). Indeed, the practical relevance of the two crucial components of the BCOM (Accounting) programme cannot be overemphasized. However, on relative basis, programme duration (of the BCOM programme) has the highest mean ranking (of 2.66) and thus minimum improvement is proposed. This is so since the duration of the BCOM programme was standard with offerings by other universities. Again relatively, graduates were satisfied with the delivery of theoretical knowledge of the programme (mean rank value=2.33). This finding confirms the finding in the previous table 3.10 that the more pressing problems were access to infrastructure. The results of the Friedman test is $X^{2}(9)=27.699, \mathrm{p}=.001$, and it shows that there is a significant difference in graduates opinions rating about the degree. It is also obvious that some components of the BCOM programme need to be improved.

Use of Knowledge and Skills Acquired during Studies: Graduates were asked to evaluate the extent to which they utilized the knowledge and skills acquired in various courses/modules during their studies in their current jobs. Table 3.12 summarises the mean ranking of the extent to which the graduates utilised the knowledge and skills they acquired in their current jobs. A lower mean ranking means the response is in the affirmative. That is, the knowledge is highly demanded in their jobs and vice versa (see scale below table 12).

Table 12: Rating of the Use Knowledge and Skills Acquired during Studies

\begin{tabular}{ll}
\hline Ranks & Mean Rank \\
\hline Knowledge/Skill & 1.50 \\
Skills) & 1.68 \\
Financial Accounting & 1.84 \\
Auditing & 1.89 \\
Computer Applications & 1.98 \\
Mathematics & 2.05 \\
Business Management & 2.11 \\
Taxation & 2.11 \\
Business Finance & 2.54 \\
Economics & 2.58 \\
Commercial Law & 2.69 \\
Public Administration & 2.78 \\
Statistics & 2.90 \\
Local Government & 3.03 \\
Development Management & 3.12 \\
Human Resource Management & 3.50 \\
Tourism Management & \\
\hline
\end{tabular}

Question: To what extent do you use knowledge acquired during your studies in the following areas for your current job? Scale: $1=$ to a very high extent, 2=to a high extent, 3=barely, $4=$ not at all

From the responses in Table 12, the graduates indicated that their jobs demanded knowledge of English Communication Skills above all other skills. It is also clear from the table that the knowledge and skills that rank second in terms of work place utilisation are those gained in the specialisation courses/modules (i.e. financial Accounting and Auditing) together with the generic skills courses/modules of English communication skills and computer skills. The Friedman test was used to justify whether these differences in mean rankings were significant. The results of the test were as follows: $X^{2}(15)=126.69$, $\mathrm{P}=.000$. The Friedman test confirmed that there was a significant difference i.e. the knowledge and skills in some courses of greater practical significance at the work place than others. Our findings here mirror those of Zembere and Chinyama (1996) who analysed the changes in the career pattern of University of Malawi graduates and found that graduates were satisfied with the training provided by the university in terms of teaching quality, course content and the knowledge gained. In addition, respondents rated the use of professional knowledge and skills acquired during studies as a very important factor in job 
satisfaction. Their findings, like ours, further show that English communication skills were seen as very important across all degrees.

Discussion: $54 \%$ of the graduates who participated in this study were females as compared to $46 \%$ who were males. This result is not surprising as it mimmicks the general trends in enrolment rate at the University of Venda over the years with the current (2012) enrolment rate standing at 51\% female and $49 \%$ male. However, based on their academic performance ( measured by the number of years it took for them to complete the 3 year BCOM (Accounting degree)), male graduates took one year less to complete the 3 year programme than their female counterparts. On the average, while the male graduates completed the BCOM degree in 4 years, female graduates completed the programme in 5 years. The median number of years for the participating graduates to complete the 3 year BCOM was found to be 4 years. This finding therefore calls for a more rigorous and rigid selection of potential applicants who meet the admission requirements to enrol in the programme in order to improve chances of completing the degree programme within the stipulated number of years. The findings of the study revealed that the main factor that influenced graduates' decision to enrol at UNIVENfor the BCOM degree was affordability of student fees.UNIVENstill remains one of the tertiary institutions in South Africa with the lowest tution and related fees, and therefore affordable to potential students, particularly those from low income households.

One of the analyis found that only $23 \%$ of the graduates were employed in the private sector. The private sector, being usually the major creator of employment, was expected to absorb more graduates than the public sector. Thus, in the case of UNIVENgraduates, the question arises as to whether the training acquired was attractive enough for the private sector or there were other reasons for the private sector shunning the employment of UNIVENgraduates or it is just a preference for public sector employment by the graduates.While most graduates felt that the BCOM (Accounting) degree adequately prepared students to adapt to the deamands of the work place, they also felt that it was not easy to get a job. The participating graduates also indicated that the most important factors that enabled them to secure a job were their field of study i.e. Accounting, and their personality. The reputation of the university played a minimal role in the graduate getting employed. This is probably due to potential employers knowing less about UNIVENand the competence of its graduates compared to more established historically advantaged universities in South Africa. As regards teaching and learning conditions and support facilities, the graduates opined that UNIVENwas a good place to meet, study and make friends with other students. They also rated consultation with, and assistance by lecturers to be good. Graduates, however,rated university infrastructure, in particular accommodation and catering facilities as being unsatisfactory. Our findings are similar to those of Ugwuonah and Omeje (1998) who investigated the adequacy or otherwise of contemporary higher education in the context of manpower development needs of the manufacturing sector in Nigeria and found that graduates were satisfied with the study environment including teaching quality of lecturers, contacts with fellow students and academic advice offered. Availability of teaching equipment, teaching materials, stocking of libraries received low scores. Infrastructural facilities such as quality of buildings, accommodation and catering facilities also recorded poor scores. In a similar vein, Kaijage's (2001) tracer study of the Faculty of Commerce and Management (FCM) graduates of the University of Dar es Salaam, found that BCom graduates generally considered the strong contacts between students to be the greatest benefit of the course, followed by the quality of FCM lectures and the sound structure of the BCom programme.

From the findings of the study, it is abundantly clear that the components of the BCom (Accounting) programme that need major improvement to increase the employability of graduates are: training in practical skills; using computers in Accounting training; as well as improvement in teaching and delivery methods. The implications of these findings are that the tutorial system and practical use of computers in Accounting education at UNIVENhave to receive urgent attention in order to improve the quality and marketability of Univen's Accounting graduates. The institution has to seriously consider introducing student internship as an essential component of the BCom (Accounting) programme. Another specific finding from the study indicates that modules offered in the BCom (Accounting) programme were relevant to the graduates' job needs. In particular, graduates indicated that skills acquired from specialisation modules in Accounting and Auditing, together with mastery of English CommunicationsSkills are very useful in their work place.Again our findings here mirrorthose of Zembere and Chinyama (1996), who analysed the changes in the career pattern of University of Malawi graduates and found that graduates were satisfied with the training provided by the university in terms of teaching 
quality, course content and the knowledge gained. In addition, respondents rated the use of professional knowledge and skills acquired during studies as a very important factor in job satisfaction. Their findings, like ours, further show that English communication skills were seen as very important across all degrees.

\section{Conclusion}

The purpose of this study was to assess the impact of the BCOM (Accounting) programme in generating skills and knowledge to satisfy the employment needs of graduates from the University of Venda. The findings of the study are similar in many respects to studies in other African countries (Nigeria, Tanzania and Malawi). The study therefore adds to the body of studies in Africa which assess the effectiveness of tertiary education in meeting the employment needs of graduates. The results of the research show the importance of emphasizing English communication and Computer skills in the structure of the BCOM (Accounting) curriculum. The study also reveals that conducive teaching and learning environment, coupled with basic infrastructural provision, is sine qua non for quality provision of accounting education at the University of Venda.

Recommendations: From the summary of findings and conclusions, the following recommendations are made:

- It is strongly recommended that the School of Management Sciences establish a system of monitoring graduates, as a way of getting a feed-back on its programme offerings, by constantly updating the database of past graduates including email and other contact addresses. In this regard, the School of Management Sciences Alumni Association is also urged to keep an up to date database of all alumni for easy contact between the School and the graduates.

- With the finding that students in the BCOM programme taking up to 5 years to complete, it is recommended that the School/Department adheres to strict selection criteria for potential applicants to enrol in the programme in order to improve chances of completing the degree programme within the stipulated number of years.

- It is also recommended that the BCOM (Accounting) programme be restructured to strenghten the modules in high demand in the work place including Computer-related modules, English communications, and Accounting and Auditing

- It is further recommended that practical training through internship (industrial attachment) should be made a part and parcel of the BCOM (Accounting) education at Univen

- These recommendations would serve as basis for enhancing the quality of Accounting education in a historically disadvantaged tertiary institution such as UNIVENand would at the same time assist the university to fulfil the fitness of purpose as well as the fitness for purpose of the BCOM (Accounting) programmes in the grand national scheme of human resource development and planning strategies of the country.

Limitation(s) of the Study: The study included only graduates who were employed or partially employed, leaving out the opinions of those graduates who were unemployed. This may be attributed to the already alluded to challenge of the absence of any reliable database with information on contact details of all graduates. Despite this limitation, the study served as an exploratory one, which has nonetheless been used to shed some light on the experiences and challenges of employed UNIVENBCOM (Accounting) graduates in the job market, as well as data gathering challenges in conducting tracer studies.

\section{References}

Association of African Universities. (2002). Regional workshop on tracer studies of past university students. University of Namibia: From the $7^{\text {th }}$ to $11^{\text {th }}$ January 2002.

City Press. (2007). BCom degrees shocker: Lowly qualifications mean graduates are unemployable by Chuenyame, Gershwin.

Harvey, L. (2000). New Realities: The Relationship Between Higher Education and Employment. Tertiary Education and Management, 6, 3-17

Human Sciences Research Council (HSRC). (2000). First Employment Experiences of Graduates (Pretoria, HSRC).

International Labour Organization (ILO) Thesaurus. (1996-2013). http://www.ilo.org/public/english/ 
Kaijage, E. (2001). Knowledge and Skills of B.Com Graduates of the Faculty of Commerce and Management in the Job Market, University if Dar-es Salaam.

Schomburg, H. (2003). Hand book for Graduate Tracer Studies. Published by Deutsche Gesellschaftfür Technische Zusammenarbeit (GTZ) GmbH and Centre for Research on Higher Education and Work, University of Kassel, Germany.

Shongwe, M. \& Ocholla, D. (2011). A tracer study of LIS graduates at the University of Zululand, 2000 20091. Paper presented at the 6th Biennial ProLISSA Conference, Pretoria, 9 -11th March 2011.

Ugwuonah, G. E. \& Omeje, K. C. (1998). Final Report of Tracer Study Research Project on Higher Education and Work. Institute for Development Studies, University of Nigeria, Enugu Campus. http://www.aau.org/studyprogram/notpub/ugowomeje.pdf

Zembere, S. N. \& Chinyama, N. P. M. (1996). The University of Malawi Graduate Tracer Study. University of Malawi. Blantyre. http://www.aau.org/studyprogram/notpub/ZEMBERE.pdf. 